\title{
EFEITOS DO OXIFLUORFEM NA FECUNDIDADE E NO TEOR DE PROTEÍNAS DO CARAMUJ O Biomphalaria glabrata
}

RONALDO C. SILVA*

MAURICYA. DA MOTTA**

FRANCISCO F. AMÂNCIO***

ANA M. M. A. MELO****

\begin{abstract}
Foram estudadas alterações na fecundidade e no teor protéico do sistema reprodutor de moluscos adultos $B$. Glabrata expostos ao oxifluorfem. O objetivo maior deste estudo foi detectar indução genotóxica em 6 grupos de 10 animais selecionados e segregados. Um grupo controle não teve contatos com o herbicida e os restantes foram expostos ao oxifluorfem (Goal@BR) em concentrações de 125; 0,$25 ; 0,5 ; 0,75$ e 1 ppm durante 10 dias. Os resultados mostraram redução da fecundidade, dependente da dose até a concentração de $0,25 \mathrm{ppm}$ do herbicida, porém nas doses maiores houve razoável aumento no número de ovos liberados em relação ao grupo controle. Foi observada alteração do conteúdo protéico com perda de $22 \%$ a $72 \%$ das bandas, analisadas por SDS-PAGE. Não foi detectada proteína hsp70, sugerindo ausência de estresse oxidativo nas concentrações utilizadas.
\end{abstract}

PALAVRAS-CHAVE: OXIFLUORFEM; Biomphalaria glabrata; MOLUSCO; HERBICIDA.

* Bacharel em Ciências Biológicas, Departamento de Biofísica e Radiologia (DBR), Universidade Federal de Pernambuco (UFPE) Recife, PE (e-mail: rcsilva@yahoo.com.br).

** PhD. em Biofísica, Professor Associado, DBR/UFPE Recife, PE (e-mail: motta@ufpe.br).

*** PhD. em Tecnologia Nuclear Aplicada, Professor Adjunto, DBR/UFPE Recife, PE (e-mail: amancioff@ufpe.br).

*** PhD. em Tecnologia Nuclear Aplicada, Professora Adjunta, DBR/UFPE Recife, PE (e-mail: amdemelo@hotmail.com). 


\section{INTRODUÇÃO}

Com o crescimento da agricultura, da indústria e da população humana tem ocorrido crescente contaminação da biosfera causada pelo uso não-controlado de produtos químicos. Isto é preocupante devido aos sérios danos provocados nos ecossistemas e na saúde ambiental, ameaçando a conservação da biodiversidade do planeta (DEPLEDGE, 1996; BICKHAM et al., 2000; KLEINJANS e SCHOOTEN, 2002; NAKANO et al., 2003; JHA, 2004). Esses poluentes quando liberados no meio ambiente podem ser acumulados no ar, no solo e na água (CLAXTON, HOUK e HUGHES, 1998; OHE et al., 2004). Entretanto, os ecossistemas aquáticos são os recipientes finais de muitos dos compostos químicos utilizados nas atividades humanas (JHA, 2004; OHE, WATANABE e WAKABAYASHI, 2004).

A ação de substâncias genotóxicas em populações naturais pode ser expressa em curto prazo, ocasionando mortes (BICKHAM et al., 2000; NAKANO et al., 2003), ou induzindo mutações que podem ser transmitidas para gerações futuras (DEPLEDGE, 1996; BICKHAM et al., 2000; KLEINJANS e SCHOOTEN, 2002; NAKANO et al., 2003; JHA, 2004). Essas substâncias podem atingir células somáticas, causando morte ou disfunção celular, gerando processos cancerosos (DEPLEDGE,1996; BICKHAM et al., 2000; JHA, 2004; MATSUMOTO et al., 2006; DI PAOLO, 2006; SOUZA, 2007).

As mutações em células germinativas podem promover alterações na variabilidade genética (DEPLEDGE, 1998; BICKHAM et al., 2000) e na freqüência alélica, levando a efeito de cunho ecológico (efeito gargalo de garrafa) e/ou evolutivo (extinções) em tempo variável (BICKHAM et al., 2000; NAKANO et al., (2003).

No Brasil, considerado o segundo maior consumidor de agrotóxicos do mundo (RODRIGUES, 2006), são usadas cerca de 150.000 toneladas desses produtos ao ano (STOPPELLI, 2005), o que envolve mais ou menos 300 ingredientes ativos e 2000 formulações (DOMINGUES et al., 2004). A agroindústria, devido ao uso abusivo e desordenado de agrotóxicos, tornou-se o segundo maior poluidor dos recursos hídricos do planeta (BEDOR et al., 2007).

A Organização Mundial de Saúde (OMS) revelou que anualmente cerca de 3 milhões de pessoas sofrem algum tipo de intoxicação relacionada com os agrotóxicos, ocorrendo 220 mil mortes/ano (VEIGA et al., 2006). No Brasil, cerca de 400 mil pessoas são contaminadas por algum tipo de agrotóxico e 4000 vêem a óbito todos os anos (PERES et al., 2005). Alguns efeitos conhecidos são: destruição de membranas eritrocitárias por agrotóxicos a base de glicina (BATISTA et al., 2006), alterações comportamentais, distúrbios sensoriais e depressão de centros vitais (respiração), alterações no equilíbrio sódio/potássio nas membranas dos axônios provocando impulsos nervosos constantes, convulsões, paralisias, promoção e potencialização de tumores (D'AMATO, TORRES e MALM 2002).

O oxifluorfem (2-chloro- $\alpha, \alpha, \alpha$-trifluoro-p-tolyl 3-ethoxy-4-nitrophenyl ether), herbicida de contato, é indicado para controle de ervas daninhas, gramíneas e plantas de folhas largas em aplicações de pré-emergência e/ou pós-emergência (SCRANO et al., 2004; DOW AGROSCIENCES, 2007), que necessita de luz para afetar a planta alvo (PEREIRA, 1987; SCRANO et al., 2004). Como os herbicidas contendo difenil-éter exercem atividade fitotóxica, impedindo a formação de clorofila nas plantas pela inibição da protoporfirinogenio oxidase $(\mathrm{RIO}, 1997)$, são recomendados para as culturas de cana-deaçúcar, (intensamente utilizado), de algodão, arroz, café, citros, pinus e eucalipto (PEREIRA, 1987; DOW AGROSCIENCES, 2007). O emprego de sistemas biológicos capazes de detectar tais efeitos assume grande importância (ARIAS et al., 2007). Muitos estudos de poluição aquática têm sido realizados com peixes, havendo carência de dados acerca de poluentes em invertebrados de água doce (NAKANO et al., 2003).

O molusco Biomphalaria glabrata (SAY, 1818) vem sendo utilizado como indicador ambiental, tanto para agentes físicos (OKAZAKI, ANDRADE e KAWANO, 1996; MELO, OKAZAKI e KAWANO, 1996; MELO, 1998; MOTTA, CARVALHO e MELO, 2001; TALLARICO et al., 2004) quanto químicos (EKABO et al., 1996; GUERREIRO et al., 1997; NAKANO et al., 2003; OLIVEIRA-FILHO, LOPES e PAUMGARTTEN, 2004; ESTEVAN et al., 2006; OLIVEIRA-FILHO, GRISOLIA e PAUMGARTTEN, 2007). Isso se deve a sua ampla distribuição geográfica, curto ciclo de vida, facilidade na coleta e 
manutenção, acomodação às condições laboratoriais e por se reproduzir o ano inteiro (OKAZAKI, ANDRADE e KAWANO 1996; MELO, 1998; NAKANO et al., 2003; TALLARICO et al., 2004; ESTEVAN et al., 2006; CANTINHA, 2008).

Para a monitoração de poluentes do meio ambiente $B$. glabrata vem sendo usado na detecção de indução de mutações em células germinativas por meio do teste do letal dominante, técnica que possibilita a observação da absorção e ativação metabólica de mutágenos químicos existente na água (NAKANO et al., 2003; TALLARICO et al., 2004; ESTEVAM et al. 2007). Essas mutações são as principais responsáveis por alterações no padrão genético dos organismos em áreas poluídas, com perda de diversidade biológica que pode levar à redução dos padrões de fecundidade e fertilidade nos descendentes (DEPLEDGE, 1996). De acordo com a Agência Nacional de Vigilância Sanitária brasileira, o limite máximo de contaminante de valor toxicológico para o oxifluorfem (i.e. de N-nitrosaminas) é 1,0 ppm (ANVISA, 2007). Tais fatos despertaram o interesse de avaliar a toxicidade de oxifluorfem em concentrações inferiores a 1 ppm sobre invertebrados aquáticos da espécie $B$. glabrata.

Os efeitos tóxicos dos poluentes químicos começam ao nível sub-celular, cujas interações desses com proteínas, ácidos nucléicos, organelas e membranas celulares ocasionam disfunções nas vias metabólicas normais e em processos bioquímicos (GUERRERO et al., 1997). A ação de oxifluorfem (concentrações: $3 ; 1,5$ e 0,75 mg/L) sobre a expressão da proteína HSP 70 (Western Blotting) em fígados e rins de tilápias (Oreochromis niloticus) mostrou aumento tempo-dependente na expressão das formas constitutiva (hsp75) e induzida (hsp73), indicando altos níveis de estresse. Esse efeito foi confirmado pelo estudo de enzimas de estresse oxidativo em peixes da mesma espécie, que evidenciou aumento na quantidade de proteínas hsp70 no fígado, alta atividade da catalase e da glutationa s-transferase, além de inibição da atividade da superóxido dismutase (PEIXOTO et al., 2006). Isto demonstrou a presença de formas reativas de oxigênio, indutoras de danos oxidativos no sistema biológico. O oxifluorfem também causou redução dos teores de DNA, RNA e proteína em mudas de juta (Hibiscus canabinus) na razão inversa das doses crescentes do tratamento (KAMBLE, 2005).

Para avaliar os possíveis efeitos na fecundidade e também no teor protéico do sistema reprodutor de moluscos adultos $B$. glabrata foi desenhado protocolo de estudo para observar alterações na produção de ovos e identificar modificações no perfil das proteínas do sistema reprodutor desses caramujos, como expressão da ação tóxica do oxifluorfem.

\section{MATERIAL E MÉTODOS}

Os efeitos da exposição sub-crônica ao herbicida oxifluorfem foram avaliados em 80 moluscos B.glabrata pigmentados, adultos jovens e sexualmente maduros da linhagem selvagem, com diâmetro entre 10 e 17 milímetros de concha. Essa amostra foi dividida em 8 grupos de 10 caramujos, sendo 7 grupos expostos ao herbicida oxifluorfem (GoalBR®) e 1 grupo não (controle). As 7 concentrações do herbicida foram baseadas no limite definido pela Agência Nacional de Vigilância Sanitária que isenta de danos significativos em organismos as concentrações de até $1 \mathrm{ppm}$ de oxifluorfem (ANVISA, 2007). O herbicida concentrado a $240 \mathrm{~g} / \mathrm{L}$ foi diluído em água filtrada e desclorada em concentrações de 0,$0625 ; 0,125 ; 0,25 ; 0,5 ; 0,75 ; 1$ e 2 ppm e distribuídas em aquários plásticos (200 mL de capacidade) junto com os caramujos. A exposição ocorreu pelo período de 10 dias consecutivos, efetuando-se a troca da solução com o herbicida diariamente. Para a manipulação do herbicida foram usados todos os equipamentos de segurança exigidos para proteção individual (óculos, máscara com filtro de ar, guarda-pó e luvas), além de câmara de exaustão (Permution $\left.{ }^{\circledR}\right)$ para a eliminação de prováveis substâncias voláteis.

Os animais foram mantidos em estufa a $25 \pm 1^{\circ} \mathrm{C}$ com fotoperíodo de 12 horas, durante 0 período de exposição, sendo alimentados diariamente com alface orgânica fresca e água com herbicida ad libitum, trocadas diariamente, exceto o grupo controle que recebeu água sem herbicida. 


\subsection{FECUNDIDADE}

Ao término do período de exposição, os animais foram cuidadosamente lavados em água filtrada corrente e colocados em aquários individuais contendo água filtrada e desclorada durante 15 (quinze) dias. Ao longo desse período, as desovas de cada caramujo foram coletadas e também observados os parâmetros de fecundidade. Para isto foram distribuídos retalhos $(4 \mathrm{~cm} \times 4 \mathrm{~cm})$ de filme polimérico (polipropileno) sobre a superfície líquida de cada aquário, nos quais coletaram-se as desovas. Após separação das massas de ovos, contou-se o número de ovos de cada massa. Esses também foram caracterizados por exame visual em microscópio estereoscópio (Tecnival-SQZ, China).

\subsection{ANÁLISE PROTÉICA}

$\mathrm{Na}$ análise protéica por eletroforese SDS-PAGE foram utilizados 12 caramujos jovens e sexualmente maduros, com diâmetro de concha de 10 a 17 milímetros. Os caramujos, separados em 6 grupos com 2 animais cada, foram expostos durante 10 dias consecutivos às seguintes concentrações do herbicida oxifluorfem (Goal ${ }^{\circledR} \mathrm{BR}$ ): 0 (controle); 0,125; 0,25; 0,5; 0,75 e 1,0 ppm. A exposição seguiu as mesmas condições descritas anteriormente.

\subsubsection{Obtenção de amostras}

Após a exposição, os caramujos foram lavados em água filtrada e dissecados pelo método de RIBEIRO-COSTA (2006) modificado. Os moluscos foram colocados em peneira e expostos ao vapor de água a $100^{\circ} \mathrm{C}$ por cerca de 5 (cinco) minutos para liberação das partes moles da concha. Retirouse, com o auxílio de pinças, o corpo do animal que foi imerso em solução salina a 0,2\%.

Procedeu-se a dissecação, com auxílio de estiletes, sendo separados e retirados os órgãos do aparelho reprodutor. As peças foram colocadas em tubos Eppendorf de microcentrífuga, com capacidade para $1,5 \mathrm{~mL}$, contendo $0,5 \mathrm{~mL}$ de solução salina a $0,2 \%$. Em seguida, com o auxílio de pistilo de polietileno, efetuou-se a maceração do material. As amostras maceradas foram centrifugadas em microcentrífuga com sistema de refrigeração (VISION - VS15000 CFN II) a 4000 rpm durante 5 (cinco) minutos, a $4^{\circ} \mathrm{C}$. Após a centrifugação, o precipitado foi desprezado e o sobrenadante guardado em baixa temperatura $\left(4^{\circ} \mathrm{C}\right)$ até a realização das análises por eletroforese.

\subsubsection{Dosagem das Proteínas}

A eletroforese por SDS-PAGE, técnica eficiente na detecção de bandas protéicas de diferentes espécies animais, é de fácil manuseio, confiável e de baixo custo. Para a padronização da concentração protéica das amostras submetidas à eletroforese foi realizada a dosagem protéica. Mediu-se o nível de concentração protéica pelo método de Bradford, utilizando soro albumina bovina (BSA) como amostra padrão (BRADFORD, 1976). As dosagens foram realizadas em espectrofotômetro, modelo Smart Spec ${ }^{\mathrm{TM}} 3000$ (fabricado pela Bio-Rad Ltda., S.Paulo, SP), usandose comprimento de onda de $595 \mathrm{~nm}$.

\subsubsection{Eletroforese em Gel de Poliacrilamida}

Os géis foram preparados em sistema de eletroforese vertical, empregando-se espaçadores de aproximadamente $0,75 \mathrm{~mm}$. Utilizaram-se géis de corrida com concentrações de $10 \%$ de poliacrilamida, seguindo a metodologia de LAEMMLI (1970). Os géis de empacotamento foram preparados com poliacrilamida na concentração de $4,5 \%$, totalizando 7 amostras: 5 de macerados do aparelho reprodutor dos animais expostos ao herbicida, 1 de macerados do aparelho reprodutor dos caramujos controles e 1 do padrão protéico (BIO-RAD). 
Após o preparo, as amostras foram homogeneizadas e diluídas na proporção de 1:1 em tampão de amostra (0,6 mL, pH 6,8; $10 \%$ SDS; $50 \%$ glicerol; $1 \%$ azul de bromofenol; $0,5 \mathrm{~mL}$ de mercaptoetanol; $0,9 \mathrm{~mL}$ de água destilada). Posteriormente, foram colocadas em água a $100^{\circ} \mathrm{C}$ durante 5 (cinco) minutos.

Utilizou-se sistema vertical de eletroforese V 10-CDC da Biosystems (São Paulo, SP), acoplado em fonte Shandon Southern - Vokam (Shandon Instruments, Inc., Sewickley, PA) com tensão constante de $150 \mathrm{~V}$, contendo tampão de corrida (Tris, $3 \mathrm{~g}$; glicina, 14,4 g; SDS 0,1\%, $1 \mathrm{~g} \mathrm{em} \mathrm{pH} \mathrm{8,3).}$ Após a corrida, as proteínas foram fixadas e coradas com nitrato de prata mediante técnicas de rotina (HARLOW e LANE, 1988).

\subsection{ANÁLISE ESTATÍSTICA}

Efetuou-se comparação entre os grupos controles e os grupos expostos dos testes de fecundidade e de fertilidade pela metodologia usada por DUNNET (1955), aplicando-se o teste do Chi Quadrado $\left(\chi^{2}\right)$ para independência, com 1 e 5 graus de liberdade e $5 \%$ de significância, com base nas seguintes hipóteses: 1) $\mathrm{HO}=$ a proporção de fecundidade do grupo controle é igual à dos grupos expostos ao herbicida; 2) $\mathrm{H} 1$ = a proporção de fecundidade do grupo controle é diferente daquela dos grupos expostos ao herbicida.

\section{RESULTADOS E DISCUSSÃO}

\subsection{FECUNDIDADE}

A redução na fecundidade variou bastante entre as concentrações, ficando entre 41,63\% e 86,89\% (Tabela 1). Todas as concentrações mostraram inibição da oviposição com significância estatística.

\section{TABELA 1 - FECUNDIDADE DO B. glabrata DURANTE 15 DIAS DE EXPOSIÇÃO SUB- CRÔNICA AO HERBICIDA OXIFLUORFEM E GRUPO CONTROLE}

\begin{tabular}{ccc}
\hline Concentração $(\mathrm{ppm})$ & Fecundidade & Redução \% \\
\hline 0,0000 & 1266 & 0,0 \\
0,0625 & 739 & $41,63^{\star}$ \\
0,1250 & 579 & $54,27^{*}$ \\
0,2500 & 166 & $86,89^{*}$ \\
0,5000 & 733 & $42,10^{*}$ \\
0,7500 & 623 & $50,79^{*}$ \\
1,0000 & 763 & $42,89^{*}$ \\
2,0000 & 681 & $46,21^{*}$ \\
\hline
\end{tabular}

*valores estatisticamente significantes pelo teste do $\chi^{2}$.

Nota-se que a maior inibição da fecundidade ocorreu com um quarto da concentração máxima tolerável, segundo a ANVISA (2007).

As alterações na fecundidade de B. glabrata, ocasionadas por agentes químicos (como os 
herbicidas), parecem diferir de outros agentes considerados genotóxicos, como as radiações ionizantes. Os efeitos da radiação gama sobre a sobrevivência e reprodução de $B$. glabrata estimulou a fecundidade em todas as doses aplicadas, atingindo níveis superiores aos do grupo não-irradiado (CANTINHA, 2008).

A Tabela 1 mostra que o efeito tóxico do herbicida foi quase linear até a dose de 0,25 ppm, quando ocorreu a menor fecundidade observada neste experimento, resultando em correlação inversa muito alta $(-0,99823)$. As doses maiores inibiram essa redução e aumentaram a postura de ovos mantendo-a em patamar médio e 3,5 vezes maior até à concentração final (2,0ppm), porém com correlação muito baixa $(-0,13395)$. A correlação final entre todas as doses e seus efeitos foi positiva e baixa $(0,29631)$, evidenciando comportamento bifásico na resposta da fecundidade. Supõe-se que essa seja a reação do sistema reprodutor, que ao chegar ao nível crítico de intoxicação aumenta a fecundidade na tentativa de manter a espécie. Porém, a elevação das concentrações do herbicida aumentaria a inviabilidade dos embriões, resultando em ovos vazios como reportado por CANTINHA (2008) com as doses maiores de radiação gama. A fecundidade se manteve em nível mais alto que o grupo não-irradiado (efeito hormético) até o limite de dose em que certamente ocorreu falência do sistema reprodutivo por lesões químicas agudas. A Tabela 1 mostra que não houve redução do patamar médio de fecundação até a dose de 2 ppm.

\subsection{ANÁLISE PROTÉICA}

Pelos perfis protéicos obtidos na eletroforese foram detectadas 18 bandas protéicas com massa molecular relativa $\left(\mathrm{M}_{\mathrm{r}}\right)$, variando de 177,26 a 12,47 KDa na amostra correspondente às gônadas de animais não-expostos. Nas amostras de animais expostos às concentrações de 0,$125 ; 0,25 ; 0,5$; 0,75 e 1 ppm de oxifluorfem foram detectadas $17,15,9,17$ e 16 bandas, respectivamente, com $M_{r}$ também variando de 200,00 a 14,4 KDA (Figura 1).

\section{FIGURA 1 - PERFIL PROTÉICO DE MACERADO DE GÔNADAS DE MOLUSCOS B. glabrata EXPOSTOS E NÃO-EXPOSTOS AO HERBICIDA (GOAL $\left.{ }^{\circledR} B R\right)$}

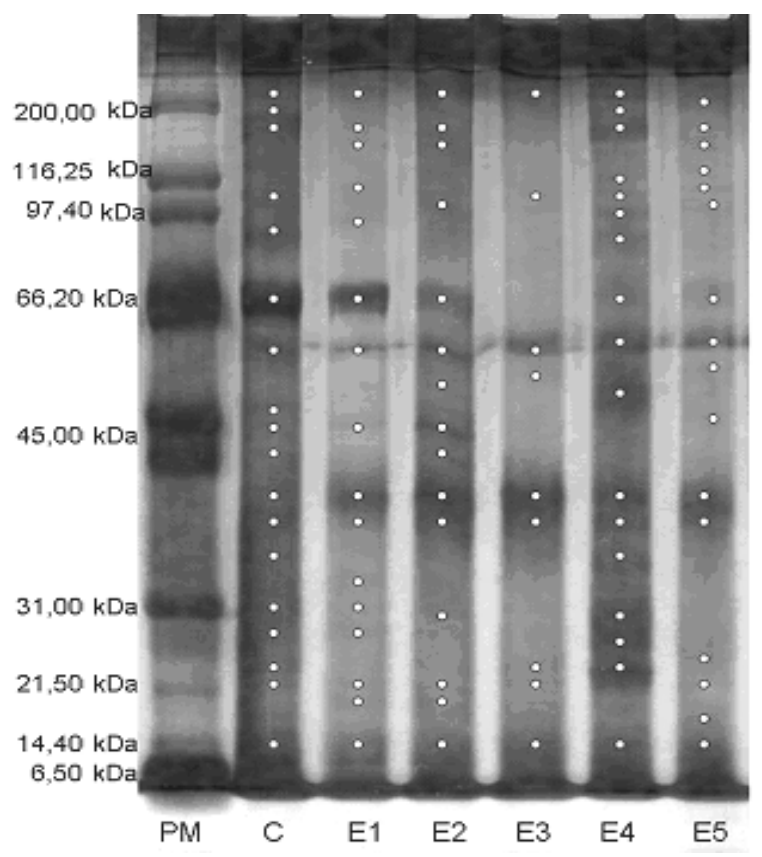

Gel de poliacrilamida a 10\%: $\mathrm{PM}=$ massa molecular relativa; $\mathrm{C}=$ grupo controle; $\mathrm{E} 1=$ grupo exposto a $0,125 \mathrm{ppm}$; $\mathrm{E} 2$ = grupo exposto a 0,25 ppm; E3 = grupo exposto a 0,5 ppm; E4 = grupo exposto a 0,75 ppm; E5 = grupo exposto a $1 \mathrm{ppm}$ do herbicida. 
Bandas com $M_{r}$ de 200,00; 65,15; 33,92; 31,33 e 14,40 KDa foram detectadas em todas as amostras, tanto no grupo controle quanto nos grupos expostos.

O caramujo Biomphalaria straminea tratado com dose progressiva de raios gama de baixa taxa de irradiação revelou fecundidade menor do que a dos controles. Quando tratados com radiação mais elevada também mostraram reação mais intensa à agressão com aumento da produção de ovos de modo semelhante à encontrada por MOTTA e MELO (1997).

A comparação entre as bandas do grupo controle (C1) e grupos expostos (E1, E2, E3, E4 e E5) revelou similaridade que variou de $82,36 \%$ a $56,25 \%$ (Tabela 2) e perdas significativas de bandas com $\mathrm{M}_{\mathrm{r}}$ de 162,48; 100,67; 48,04; 45,99 40,36; 27,28; 21,95; 20,12 e 16,9 KDa, correspondendo a $77,5 \%$ das bandas perdidas nas amostras provenientes de animais expostos.

\section{TABELA 2 - ANÁLISE DO PERFIL PROTÉICO POR ELETROFORESE SDS-PAGE DE GÔNADAS DOS MOLUSCOS B. glabrata, EXPOSTOS E NÃO-EXPOSTOS A DIFERENTES CONCENTRAÇÕES DO HERBICIDA OXIFLUORFEM POR 10 DIAS}

\begin{tabular}{ccccccc}
\hline Bandas & \multicolumn{7}{c}{ Amostras } \\
\cline { 2 - 7 } & C1 & E1 & E2 & E3 & E4 & E5 \\
\hline $\begin{array}{c}\text { Comuns entre os grupos } \\
\text { Perdidas em relação ao grupo }\end{array}$ & 18 & 12 & 10 & 6 & 14 & 9 \\
$\begin{array}{c}\text { controle (C1) } \\
\text { Surgidas nos grupos expostos } \\
\text { (novas) }\end{array}$ & - & 6 & 8 & 13 & 4 & 9 \\
$\begin{array}{c}\text { Total } \\
\text { Similaridade (\%) }\end{array}$ & - & 5 & 5 & 3 & 3 & 7 \\
Perdas (\%) & 18 & 17 & 15 & 9 & 17 & 16 \\
& 100 & 66,66 & 66,67 & 66,67 & 82,35 & 56,25 \\
& 0 & 33,33 & 44,44 & 72,22 & 22,22 & 50,00 \\
\hline
\end{tabular}

Os maiores percentuais de perda de bandas de proteínas estavam na amostra oriunda de animais expostos às concentrações de 0,5 ppm e 1 ppm com $72,22 \%$ e 50\%, respectivamente, em relação ao grupo controle.

As bandas C, E2 e E4 mostraram-se mais escuras que as demais, talvez devido imperfeições na execução da técnica com sobrecarga nas três faixas, mas sem interferir na leitura do perfil das proteínas.

OLIVEIRA-FILHO, GRISOLIA e PAUMGARTTEN (2008) estudaram os efeitos transgeracionais da exposição crônica do nonilfenol etoxilato sobre a reprodução de $B$. tenagophila. Eles constataram redução no número de ovos por caramujos (fecundidade) e no número de desovas por caramujos na geração $F_{0}$, fato que também se repetiu na geração F1. Resultados obtidos com outros herbicidas, também demonstraram a grande sensibilidade das fases iniciais da espermatogênese a agentes genotóxicos como os agrotóxicos (OLIVEIRA-FILHO, LOPES e PAUMGARTTEN (2004); ESTEVAN et al., 2006; NAKANO et al., 2003).

GUEDES (2005) estudou o perfil protéico de embriões de B.glabrata expostos a diferentes concentrações ( $0 ; 0,25$ e 0,50 ppm) do herbicida oxifluorfem. Evidenciou a presença de bandas protéicas com diferentes massas moleculares (200,00; 66,20 e 45,00 Kda), não constatando diferenças entre os embriões expostos direta e indiretamente em relação aos embriões não-expostos.

Além das perdas de bandas no perfil protéico, 23 bandas apareceram nos grupos expostos provavelmente pela degradação das cadeias polipeptídicas inexistentes no grupo controle. Apesar da ausência de agregados nas amostras analisadas, a grande quantidade de bandas incomuns ao controle indica forte ação do herbicida sobre as cadeias polipeptídicas da gônada de $B$. glabrata sugerindo atividade proteolítica. 
Curiosamente o grupo exposto à maior dose $(1,0$ ppm) apresentou a menor similaridade de bandas com os demais grupos, mas teve a segunda menor perda protéica entre os caramujos expostos. O grupo exposto a 0,5 ppm apresentou a maior perda e a menor similaridade entre os grupos expostos, mostrando a reação do sistema reprodutor à agressão do herbicida com aumento da postura em níveis semelhantes àqueles dos animais expostos a 0,0625 ppm de herbicida. A maior similaridade de bandas com o controle ocorreu nas proteínas do segundo grupo mais concentrado, com dose de 0,75 ppm. Isto leva a crer em mecanismos desconhecidos de inibição e ativação de enzimas proteolíticas relacionados ao efeito genotóxico produzido.

\section{CONCLUSÃO}

Observou-se redução na fecundidade, dependente da dose até a concentração de 0,25 ppm do herbicida. Em doses maiores houve razoável aumento no número de ovos liberados, possivelmente devido ao limiar de reação do sistema reprodutor aos níveis de intoxicação. Doses abaixo de 1 ppm não determinaram o aparecimento de proteína hsp70, segundo os parâmetros utilizados neste ensaio, indicando ausência de estresse oxidativo em B.glabrata nas doses utilizadas. A perda de proteína variou entre $22 \%$ e $72 \%$, sendo maior na dose de $0,5 \mathrm{ppm}$. O caramujo $B$. glabrata mostrou-se bom indicador da ação genotóxica de baixas concentrações de oxifluorfem. Concentrações subletais do herbicida promoveram forte ação genotóxica sobre células germinativas provocando alterações nos padrões protéicos. Isto gerou perdas de proteínas no sistema reprodutor do caramujo, ocasionando quebras de cadeias polipeptídicas que levariam a sérios danos genéticos. Desta forma, a toxicidade desse agente deveria ser reavaliada pelos órgãos competentes visando maior proteção ambiental.

\section{ABSTRACT}

\section{EFFECTS OF OXYFLUORFEN IN FECUNDITY AND PROTEIN LEVEL OF SNAIL Biomphalaria glabrata}

Effects of Oxyfluorfen exposure on adult mollusks B. glabrata fecundity and reproduction system proteins were studied. The main objevtive of this work is to detect genotoxic inductions on egg production and on proteins profile of 6 groups of 10 selected and segregated animals. A control group didn't have contacts with the herbicide and the rest were exposed to the Oxyfluorfen (Goal®BR) at $0.125 ; 0.25 ; 0.5 ; 0.75$ and 1 ppm concentrations during 10 days Results showed a dose dependent fecundity reduction up to $0.25 \mathrm{ppm}$ of herbicide concentration. Under higher doses occurred a fairly increased egg release as compared to control group. Band losses from $22 \%$ to $72 \%$ on the SDS-PAGE analyzed protein profile were observed, induced by herbicide on exposed groups. Protein hsp70 was not detected, thus indicating an absence of oxidative stress under the used doses.

KEY-WORDS: OXYFLUORFEN; Biomphalaria glabrata; MOLLUSK; HERBICIDE.

\section{REFERÊNCIAS}

1 ANVISA. Agência Nacional de Vigilância Sanitária. Monografia do oxifluorfem. Disponível em: <http:// www.anvisa.gov.br/toxicologia/ monografia/index.htm> Acesso em: 16/08/2007.

2 ARIAS, A.R.L.; BUSS, D.F.; ALBURQUERQUE, C.; INÁCIO, A.F.; FREIRE, M.M.; EGLER, M.; MUGNAI, R.; BAPTISTA, D.F. Utilização de bioindicadores na avaliação de impacto e no monitoramento da contaminação de rios e córregos por agrotóxicos. Ciência e Saúde Coletiva, v. 12, n.1, p. 61-72, 2007.

3 BATISTA, M.T.A.; RODRIGUES, H.G.; FONSECA, L.C.; BONETTI, A.M.; PENHA-SILVA, N.; NERES, A.C.; AVERSI-FERREIRA, T.A. Estudo dos efeitos do pesticida da classe glicina substituída sobre eritrócitos humanos. Revista Eletrônica de Farmácia Suplemento, v. 3, n.1, p. 22-24, 2006.

4 BEDOR, C.N.G.; RAMOS, L.O.; REGO, M.A.V.; PAVÃO, A.C.; AUGUSTO, L.G.S. Avaliação e reflexos da comercialização e utilização de agrotóxicos na Região do Submédio do Vale do São Francisco. Revista Baiana de Saúde Pública, v. 31, n.1, p. 68-76, 2007. 
5 BICKHAM, J.W.; SANDHU, S.; HEBERT, P.D.N.; CHIKHI, L.; ATHWAL, R. Effects of chemical contaminants on genetic diversity in natural populations: implications for biomonitoring and ecotoxicology. Mutation Research, v. 463, p. 3351, 2000.

6 BRADFORD, M.M. A rapid and sensitive method for the quantitation of microgram quantities of protein utilizing the principal of protein-dye binding. Anal. Biochem., v. 72, p. 248-254, 1976.

7 CANTINHA, R.S. Influência da radiação gama de alta taxa de dose na sobrevivência e reprodução de Biomphalaria glabrata. Recife, 2008. 57 p. Dissertação (Mestrado em Tecnologias Energéticas e Nucleares), Universidade Federal de Pernambuco.

8 CLAXTON, L.D.; HOUK, V.S.; HUGHES, T.J. Genotoxicity of industrial wastes and effluents. Mutation Research, v. 410, p. 237-243, 1998.

9 D'AMATO, C.; TORRES, J.P.M.; MALM, O. DDT (Dicloro Difenil Tricloroetano): toxicidade e contaminação ambiental uma revisão. Quim. Nova, v. 25, n. 6, p. 995-1002, 2002.

10 DEPLEDGE, M.H. Genetic ecotoxicology: an overview. Journal of Experimental Marine Biology and Ecology, v. 200, p. 57-66, 1996.

11 DEPLEDGE, M.H. The ecotoxicological significance of genotoxicity in marine invertebrates. Mutation Research, v. 399, p. 109-122, 1998.

12 DI PAOLO, C. Aplicação do ensaio cometa a estudo de danos ao DNA de robalos, Centropomus parallelus (Poey, 1860), expostos à $\beta$-naftoflavona. São Paulo, 2006. 103 p. Dissertação (Mestrado em Oceanografia Biológica). Instituto Oceanográfico da Universidade de São Paulo.

13 DOMINGUES, M.R.; BERNARDI, M.R.; ONO, E.Y. S.; ONO, M.A. Agrotóxicos: risco à saúde do trabalhador rural. Semina: Ciências Biológicas e da Saúde, v. 25, p. 45-54, 2004.

14 DOW AGROSCIENCES. Manual do produto Goal* BR. Disponível em: <http://www.dowagro.com/PublishedLiterature/ dh_0163/09002f1380163ad9.p?filepath=br/pdfs/noreg/013-00058.pdf\&fromPage=GetDoc >. Acesso em: 16/08/2007.

15 DUNNET, C.W. Multiple comparison procedure for comparing several treatments with a control. J. Am. Stat. Assoc., v. 50, p.1096-1121, 1955.

16 EKABO, O.A.; FARNSWORTH, N.R.; HENDERSON, T.O.; MAO, G.; MUKHERJEE, R. Antifungal and molluscicidal saponins from Serjania salzmanniana. J. Nat. Prod., v. 59, p. 431-435, 1996.

17 ESTEVAM, E.C.; NAKANO, E.; KAWANO, T.; PEREIRA, C.A.B.; AMANCIO, F.F.; MELO, A.M.M.A. Dominant lethal effects of 2,4-D in Biomphalaria glabrata. Mutation Research, v. 611, p. 83-88, 2006.

18 GUEDES, G.M.R. Avaliação da toxicidade do oxifluorfem em moluscos Biomphalaria glabrata (SAY, 1818). Recife, 2005. 29 p. Monografia (Conclusão do Curso de Biomedicina), Universidade Federal de Pernambuco.

19 GUERRERO, N.R.V. ; MOZZARELLI, M.N.; GIANCARLO, H.; NAHABEDIAN, D.; WIDER, E. Biomphalaria glabrata: relevance of albino organisms as a useful tool for environmental lead monitoring. Bulletin of Environmental Contamination and Toxicology, v. 59, p. 822-827, 1997.

20 HARLOW, E.; LANE, D. Antibodies: a laboratory manual. New York: Cold Spring Harbour, 1988.

21 KLEINJANS, J.C.S.; SCHOOTEN, F.J.V. Ecogenotoxicology: the evolving field. Environmental Toxicology and Pharmacology, v. 11, p. 173-179, 2002.

22 JHA, A.N. Genotoxicological studies in aquatic organisms: an overview. Mutation Research, v. 552, p. 1-17, 2004.

23 KAMBLE, I.S. Effect of herbicide goal (oxyfluorfen) on DNA, RNA and protein contents of seedlings of Hibiscus canabinus Linn. Biosciences Biotechnology Research Asia, v. 3, n.2, p. 357-62, 2005.

24 LAEMMLI, U.K. Clevage of strutural proteins during the assembly of the head of bacteriophage $T_{4}$. Nature, v. 227, p. 680-685, 1970.

25 MATSUMOTO, S.T.; MANTOVANI, M.S.; MALAGUTTII, M.I.A.; DIAS, A.L.; FONSECA, I.C.; MARIN-MORALES, M.A. Genotoxicity and mutagenicity of water contaminated with tannery effluents, as evaluated by the micronucleus test and comet assay using the fish Oreochromis niloticus and chromosome aberrations in onion root-tips. Genetics and Molecular Biology, v. 29, n. 1, p. 148-158, 2006.

26 MELO, A.M.M.A. Estudo dos efeitos da radiação gama de ${ }^{60} \mathrm{Co}$ sobre fecundidade, fertilidade, crescimento e sobrevivência de Biomphalaria straminea (DUNKER, 1948). Recife, 1994. 102 p. Dissertação (Mestrado em Biofísica), Universidade Federal de Pernambuco.

27 MELO, A.M.M.A.; OKAZAKI, K.; KAWANO, T. Effect of ${ }^{60} \mathrm{Co}$ gamma radiation on Biomphalaria glabrata (SAY, 1818) embryos. Journal of Medical and Applied Malacology, Santiago, v. 8, n. 1, p. 58-59, 1996. 
28 MOTTA, M.A.; CARVALHO, E. B.; MELO, A.M.M.A. DL50 of ${ }^{60}$ Co Gamma rays applied on Biomphalaria glabrata (SAY, 1818). Bulletin of the Institute of Malacology of Tokyo, v. 3, n. 8, p. 125-129, 2001.

29 MOTTA, M.A.; MELO, A.M.M.A. Fecundity changes induced by low-doses of gamma radiation on Biomphalaria straminea. Mem. Inst. Oswaldo Cruz, v. 92, n. 4, p. 559-561,1997.

30 NAKANO, E.; WATANABE, L.C.; OHLWEILER, F.P.; PEREIRA, C.A.B.; KAWANO, T. Establishment of the dominant lethal test in the freshwater mollusk Biomphalaria glabrata (SAY, 1818). Mutation Research, v. 536, p. 145-154, 2003.

31 OHE, T.; WATANABE, T.; WAKABAYASHI, K. Mutagens in surface waters: a review. Mutation Reseach, v. 567, p. $109-149,2004$.

32 OKAZAKI, K.; ANDRADE JR., H.F.; KAWANO, T. Effect of ${ }^{60}$ Co gamma radiation on Biomphalaria glabrata (Mollusca, Gastropoda) embryos: mortality, malformation and hatching. Brazilian Journal of Medical and Biological Research, v. 29, p. 1057-1067, 1996.

33 OLIVEIRA-FILHO, E.C.; LOPES, R.M.; PAUMGARTTEN, F.J.R. Comparative study on the susceptibility of freshwater species to copper-based pesticides. Chemosphere, v. 56, p. 369-374, 2004.

34 OLIVEIRA-FILHO, E.C.; GRISOLIA, C.K.; PAUMGARTTEN, F.J.R. Trans-generation study of the effects of nonylphenol ethoxylate on the reproduction of the snail Biomphalaria tenagophila. Ecotoxicology and Environmental Safety, v. 72, p. $458-465,2008$.

35 PEIXOTO, F.; ALVES-FERNANDES, D.; SANTOS, D.; FONTAINHAS-FERNANDES, A. Toxicological effects of oxyfluorfen on oxidative stress enzymes in tilapia Oreochromis niloticus. Pesticide: Biochemistry \& Physiology, v. 85, p. 91-96, 2006.

PERES, F.; OLIVEIRA-SILVA, J.J.; DELLA-ROSA, H.V.; LUCA, S.R. Desafios ao estudo da contaminação humana e ambiental por agrotóxicos. Ciência \& Saúde Coletiva, v. 10(Sup), p. 27-37, 2005.

37 PEREIRA, W.S.P. Herbicida de pré-emergência - oxifluorfem. Série Técnica IPEF, v. 4, n.12, p. $45-60,1987$.

38 RIBEIRO-COSTA, C.S. Invertebrados: manual de aulas práticas. 2. ed. Ribeirão Preto: Holos, 2006. 271. p.

39 RIO, B.; PARENT-MASSIN, D.; LAUTRAITE, S; HOELLINGER, H. Effects of a diphenyl-ether herbicide, oxyfluorfen, on human BFU-E/CFU-E development and haemoglobin synthesis. Hum. Exp. Toxicol, v. 16, p. 115-122, 1997.

40 RODRIGUES, N.R. Agrotóxicos: análises de resíduos e monitoramento. Multiciência: Construíndo a História dos Produtos Naturais, v. 7, p. 1-7, 2006.

41 SCRANO, L.; BUFO, S.A.; CATALDI, T.R.I.; ALBANIS, T.A. Surface retention and photochemical reactivity of the diphenylether herbicide oxyfluorfen. J. Environ. Qual., v. 33, p. 605 - 611, 2004.

42 SOUZA, V.H.E. Utilização de testes citogenéticos para avaliação de mutagênese ambiental. Disponível em: < http://www.pec.uem.br/doc/VII_SAU/ trabalhos/6laudas/SOUZA20\%Vitor\%20Hugo\%20Emuno\%de.pdf>. Acesso em: 16 ago. 2007

43 STOPPELLI, I.M.B. S. Agricultura, ambiente e saúde: uma abordagem sobre o risco de contato com agrotóxicos a partir de um registro hospitalar de referência regional. São Carlos, 2005. 155 p. Tese (Doutorado em Ciências da Engenharia Ambiental), Universidade de São Paulo.

44 TALLARICO, L.F.; OKAZAKI, K.; KAWANO, T.; PEREIRA, C.A.B.; NAKANO, E. Dominant lethal effect of ${ }^{60}$ Co gamma radiation in Biomphalaria glabrata (SAY, 1818). Mutation Research, v. 561, p. 139-145, 2004.

45 VEIGA, M.M.; SILVA, D.M.; VEIGA, L.B.E.; FARIA, M.V.C. Análise da contaminação dos sistemas hídricos por agrotóxicos numa pequena comunidade rural do Sudeste do Brasil. Cad. Saúde Pública, v. 22, n. 11, p. 2391-2399, 2006. 